Keywords: Mental health, Prymary health care,

\title{
GP mental health care in 10 European countries: patients' demands and GPs' responses
}

\author{
Peter F.M. Verhaak \\ Jozien M. Bensing \\ Atie v d Brink-Muinen \\ Netherlands Institute of Health Services \\ Research \\ THE NETHERLANDS
}

\begin{abstract}
Background: There is a large variation between different countries regarding the presentation of psychological symptoms, their diagnosis and treatment in general practice. A possible explanation for such variation might be the conditions of the health care system in different countries. A gate-keeping function might be facilitating the recognition and treatment of mental disorder. Furthermore, the payment system and insurance system are considered of importance.

Method: To test these hypotheses, data were collected in 10 European countries with different health care systems. 25 - 43 GPs in each country collected data on 20 consecutive doctor-patient contacts, including videotaped consultations, patient and GP questionnaires per contact and a general GP questionnaire.

Results: There are differences, not related to health care system characteristics, between countries concerning the prevalence of mental distress among patients visiting their GP. Only a minority of distressed patients presented psychological symptoms. Although GPs did not limit their psychological diagnoses to patients presenting with psychological symptoms, they also diagnosed only a minority of distressed patients with a psychological diagnosis. In general, psychological presentation and diagnosis in gatekeeping countries and in Switzerland (where GPs were remunerated for psychological diagnosis and treatment) was more frequent than in other countries. Especially in Eastern European countries Estonia, Poland and Rumania the presentation of psychological symptoms by distressed patients was very uncommon. Psychological treatment was not related to gate-keeping. In case of Switzerland, remuneration seemed an effective incentive.

Conclusion: Overall prevalence of mental distress cannot be explained by gate-keeping function of the GP, payment system, remuneration system or differences between Eastern and Western Europe. However, a gate-keeping system appears to lower the threshold for help seeking and diagnosis. Gate-keeping has no clear impact on treatment of mental disorder in general practice. In this case, remuneration is observed to be effective.
\end{abstract}




\section{Introduction}

Mental disorders are widespread throughout the world ${ }^{1}$. However, there are considerable differences between countries regarding the proportion of recognized and treated mental health problems ${ }^{2}$. In most European countries GPs play an important role in mental health care, because the majority of mental health problems never receive more specialized treatment beyond GP care. The manner in which general practice filters mental health problems is modelled by Goldberg and Huxley, and a modified version of this is shown as Figure $1^{3}$. A series of cross-cultural studies conducted throughout the world have shown that the model appears applicable in European and most American countries. In Africa and Asia however, the role of the GP is much less pronounced $^{4}$.

In order to gain a better understanding of the differences in the treatment of mental health problems in European countries, all levels and filters in the model are of interest. At level 0 , differences in the prevalence of mental disorders in the population may possibly be responsible for variation in treatment. This may originate from dissimilar cultural values, leading to differences in perception, attribution and acceptance of mental health problems. The first filter -help seeking behaviour for mental health problems- may function differently in various countries due to differences in cultural values regarding helpseeking or due to health service characteristics influencing access to care. In general, it has been thought that a gate-keeping system facilitates help seeking in primary care, as the GP is considered the first professional for all health problems, including mental health problems. The second filter -recognition of a mental health problem by the GP- may function differently in separate countries because of variations in GPs' knowledge of their patients or because of variations in available time. In an earlier analysis concerning six of

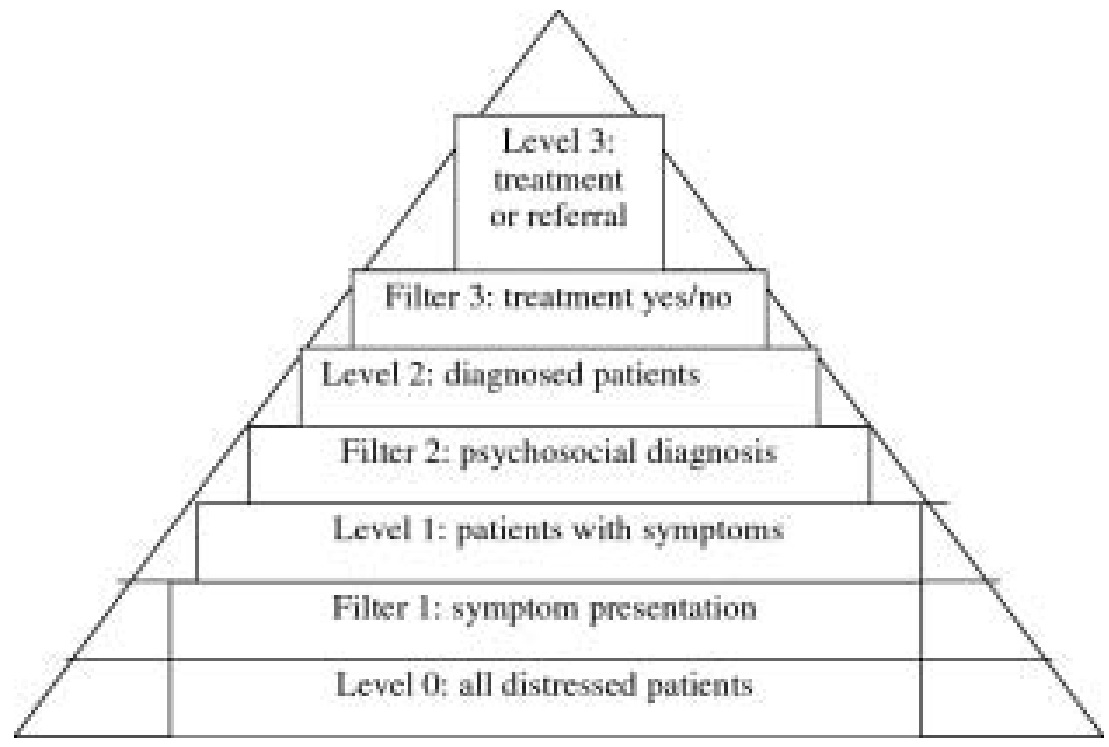

Figure 1. The pathway to mental health care: adapted from Goldberg and Huxley's Pyramid. 
the countries in our current database, we concluded that available time was most abundant in countries with a fee for service system, where competition between GPs was highest ${ }^{5}$. The third filter -referral or treatment by GPagain might be influenced by the payment system. Payment systems that reward treatment of mental disorders by the GP may keep more patients in primary care and lead to lower referral figures than payment systems that have no incentive for treatment by GPs.

Therefore, to understand the mechanisms behind the variation in recognition and treatment of mental disorder between countries, it is critical to study all these levels. The following research questions are put forward:

Are there differences between separate countries:

1) In the degree of distress experienced by patients who visit a doctor (level 0)?

2) In the degree to which feelings of distress are translated into psychological or social symptoms, presented to the GP? (filter 1)

3) In the degree to which patients with feelings of distress are diagnosed with a psychological or social disorder by the GP? (filter 2)

4) In the degree to which patients with a psychosocial diagnosis are treated by the GP? (level 2)

\section{Method}

\section{Data collection}

Data were collected in general practices in 10 European countries during the period 1997-2000. Between 25 and 43 GPs in each country participated. Each GP collected data on 20 consecutive doctor-patient contacts during consultation hours. Prior to the consultation, patients gave informed consent and completed a brief questionnaire. The consultation was videotaped with a camera installed at a fixed position in the consultation room. After the consultation, patients completed a second questionnaire and the GP registered relevant data.

\section{Samples, recruitment and response}

In general, in each country, GPs from a large region or nationwide were invited blindly to participate. Post-hoc analysis revealed that participants were in most respects and in most countries representative for their country. For more details see: vd Brink-Muinen ${ }^{6}$. Patients were asked for informed consent before they entered the study. Refusal to participate was about $20 \%$ in the Western European countries and about $8 \%$ in the Eastern European countries Psychological and social problems, according to the GPs' registration, were overrepresented in the group who refused to participate.

\section{Country characteristics}

Table I presents some healthcare system characteristics of the 10 countries, participating in this study. Among them are three countries -the Netherlands, Spain and the UK- with a gate-keeping system: patients are obliged to see a general practitioner first, before eventually being referred to specialised care. In these three countries, each patient is registered on a fixed list of a general practice, which they are supposed to visit. In five countries, Estonia, Poland, Romania, Spain and Sweden, GPs had a salary in the period when data were collected. In Belgium, Germany and Switzerland GPs worked on a fee for service basis. In 
Table I

Characteristics of study sample and health care system on country level.

\begin{tabular}{lccccc} 
& $\begin{array}{c}\text { N of participating } \\
\text { GPs }\end{array}$ & $\begin{array}{c}\text { N of } \\
\text { consultations }\end{array}$ & Gatekeeping & $\begin{array}{c}\text { Payment } \\
\text { system }\end{array}$ & $\begin{array}{c}\text { Registered } \\
\text { patients }\end{array}$ \\
\hline Belgium & 31 & 522 & - & Ffs & No \\
Estonia & 27 & 516 & - & Sal & No \\
Germany & 43 & 780 & - & Ffs & No \\
Netherlands & 31 & 487 & + & Ffs/cap & Yes \\
Poland & 35 & 678 & - & Sal & No \\
Rumania & 30 & 576 & - & Sal & No \\
Spain & 27 & 495 & + & Sal & Yes \\
Sweden & 25 & 376 & - & Sal & No \\
Switzerland & 31 & 595 & - & Ffs & No \\
UK & 27 & 441 & + & Cap & Yes \\
Total & 307 & 5466 & - & - & - \\
\hline
\end{tabular}

$* \mathrm{ffs}=$ fee for service

sal $=$ salaried

Cap = capitation fee

Switzerland GPs are remunerated for giving "psychological help". In the Netherlands, GPs received a capitation fee for patients who were compulsory insured and a fee for service for private patients.

\section{Variables and instruments}

All variables, instruments, scale composition and reliability analysis have been extensively described in vd Brink-Muinen (1999). The following outcome parameters have been used in this study.

\section{Patient}

Questionnaire before consultation:

- Functional status: Dartmouth COOP WONCA: feelings of distress ${ }^{7}$. People reporting "quite a bit" or "extremely" on feelings of distress were considered to experience "feelings of distress".

- Reasons for GP visit in patients' words (classified in International Classification for Primary Care ${ }^{8}$. Patients presenting reasons for visit, classified as "Psychological" or "Social" were considered to present "symptoms".
Registration by GP at patient level:

- Diagnosis by the GP (coded in ICPC). Patients diagnosed within the chapters "Psychological" or "Social" were considered to have been given a psychosocial diagnosis.

- Prescription of medication in combination with a $\mathrm{P} / \mathrm{Z}$ diagnosis was considered a psychopharmacological prescription.

\section{General Practitioner}

\section{Doctor-patient interaction}

Observation by Roter's Interaction Analysis System, measuring a.o.

- Verbal instrumental behaviour (questions, information-giving, counselling, advising) on psychosocial topics (mood, feelings).

\section{Analysis}

Differences between countries were assessed with one-way ANOVA and post hoc multiple comparisons with Bonferoni modification.

Possible confounding effects of patient and GP characteristics were assessed using Multi 
Level Logistic Regression Analysis. Possible confounders at level 0 (distress in the visiting population) were considered to be: the patient characteristics age, gender, living alone, employment status. ( (f $^{9-14}$ Regarding filter 1 -presenting psychosocial symptoms-), the same patient characteristics together with the importance attached by the patient to psychosocial help, familiarity with the GP, and GP's age and gender were controlled for. Differences between countries regarding filter 2 (GP's diagnosis) were tested with the patient characteristics and GP characteristics used in the former analysis, together with the GP characteristic "psychosocial task perception" and the following aspects of doctor-patient communication: psychosocial talk by GP, affective behaviour by GP, interest/concern, friendliness, eye contact and consultation length ${ }^{15-19}$.

Differences between countries regarding treatment were tested, controlling for all patient and GP characteristics and the enabling communication aspects: interest/ concern, friendliness, eye contact and consultation length.

\section{Results}

The mechanism of the filters in different countries is demonstrated in Figure 1.21\% of patients $(\mathrm{N}=956)$, visiting a GP, report feelings of distress. $15 \%$ of these patients $(\mathrm{N}$ $=143$ ) present psychological or social symptoms to their GP. As a result, 3.2\% of the patients who visit a GP are distressed and present psychological symptoms. Of those who present symptoms, $82 \%$ receive a psychosocial diagnosis as well, which means that $2.6 \%$ of the distressed patients presenting with symptoms are diagnosed by the GP.
GPs do not limit their psychosocial diagnoses to those who present with psychological symptoms. For instance, because of earlier experiences with the patient they may consider a psychological diagnosis appropriate while the patient presents with somatic symptoms. Therefore, the total proportion of distressed patients with a psychosocial diagnosis from their GP is higher: $6.7 \%$. As can be seen, there is variation between the countries at all levels. Variation increases from $15 \%-28 \%$ at level 0 (Prevalence in visiting population), to $0 \%-29 \%$ at filter 1 (presentation of symptoms) and 3\%-15\% at filter 2 (diagnosis by GP)

Research question 1: Psychosocial Distress in the population, attending general practice (Level 0)

Differences in feeling of distress between countries are relatively small but significant - analysis of variance reveals a leading position for Rumania and the UK with more than $25 \%$ of attending patients indicating feelings of distress, and Poland at the bottom with less than $15 \%$ who feel distressed. The other countries occupy a middle position with about $20 \%$ of distressed patients. $(\mathrm{F}=23.25, \mathrm{df}=9 ;$ 4469, $\mathrm{p}<.001)$. Besides these country effects, multi-level analysis indicates higher risks for women and people living alone in all countries (see Table II)

Research question 2: Help-seeking for psychosocial distress (Filter 1)

Filter 1, the decision to seek help for psychological distress, is expressed by the proportion of those who experience distress that actually present psychosocial symptoms to their GP.

There are clear and significant differences between the Eastern European countries with less than $5 \%$ of distressed patients presenting with psychosocial symptoms, 
Table II

Multilevel (logistic) regression analysis: regression coefficients (ß) and standard errors of patient and GP characteristics with respect to four outcome measures: all countries pooled****.

\begin{tabular}{|c|c|c|c|c|}
\hline & $\begin{array}{c}\text { Feeling } \\
\text { distressed }\end{array}$ & $\begin{array}{l}\text { Psychosocial } \\
\text { symptoms }\end{array}$ & $\begin{array}{l}\text { Psychosocial } \\
\text { diagnosis }\end{array}$ & $\begin{array}{l}\text { Psychosocial } \\
\text { information }\end{array}$ \\
\hline Sample involved: & $\begin{array}{l}\text { All patients } \\
\text { included } \\
\text { in the study }\end{array}$ & $\begin{array}{l}\text { All patients } \\
\text { feeling } \\
\text { distressed }\end{array}$ & $\begin{array}{l}\text { All patients } \\
\text { feeling } \\
\text { distressed }\end{array}$ & $\begin{array}{l}\text { All patients } \\
\text { feeling } \\
\text { distressed }\end{array}$ \\
\hline \multicolumn{5}{|l|}{ Patient char. } \\
\hline Age & n.s & $0.014(0.007)$ & n.s. & n.s. \\
\hline Gender & $0.608(0.088)$ & n.s. & n.s. & n.s. \\
\hline Livng alone & $0.246(0.106)$ & n.s. & n.s. & n.s. \\
\hline Employed & n.s. & n.s. & n.s. & n.s. \\
\hline \multicolumn{5}{|l|}{ Educational level: } \\
\hline - medium & n.s. & n.s. & n.s. & n.s. \\
\hline - high & n.s. & n.s. & n.s. & n.s. \\
\hline $\mathrm{N}$ of years patient & n.s. & n.s. & n.s. & n.s. \\
\hline Familiarity & - & n.s. & $-0.236(0.098)$ & n.s. \\
\hline Psychosocial importance & - & $0.773(0.103)$ & $0.695(0.122)$ & n.s. \\
\hline d-p communication & & & n.s. & \\
\hline \multicolumn{5}{|l|}{ Psychosocial talk GP } \\
\hline (mood, feelings discussed) & - & - & $0.033(0.008)$ & - \\
\hline \multicolumn{5}{|l|}{ Affective talk GP } \\
\hline (expression empathy/concern) & - & - & n.s. & $0.012(0.005)$ \\
\hline Interest/concern & - & - & n.s. & - \\
\hline Warmth/friendliness & - & - & n.s. & - \\
\hline Eye contact & - & - & $0.014(0.007)$ & $0.001(0.0003)$ \\
\hline Consultation length & - & - & $0.042(0.021)$ & $0.064(0.020)$ \\
\hline
\end{tabular}

n.s.: variables included in the final model which were not significant.

- : variables not included in the final model.

* Countries were adjusted for in all analyses, but the results are not shown in the Table.

** GP variables "age", "gender", psychosocial task perception", "perceived role of psychosocial factors" were included in the final model but were not significant.

Belgium and Germany with about $15 \%$ presenting psychosocial symptoms and the remaining countries, with $20-30 \%$ of distressed patients presenting their symptoms. $(\mathrm{F}=8.155 ; \mathrm{df}=9 ; 946 ; \mathrm{p}<.001)$. In all countries, older patients and those who attach importance to a GP discussing psychological matters have significantly higher odds in favour of expressing their psychosocial symptoms when they feel distressed (Table II).
Research question 3: Patients with a psychological or social diagnosis (Filter 2, detection by GP)

Less than $60 \%$ of patients who present with psychosocial symptoms are diagnosed as such in Belgium and Spain. In the other countries, between $75 \%$ and $100 \%$ of the patients presenting with psychosocial symptoms were given a psychosocial diagnosis. Significant differences can be found between Belgium and Spain on the one hand and the 
Netherlands, the UK and Switzerland on the other. $(\mathrm{F}=3,701 ; \mathrm{df}=8,134 ; \mathrm{p}=.001)$

Some $50 \%-60 \%$ of distressed patients (regardless of their presentation of psychosocial symptoms) are given a psychological or social diagnosis in the Netherlands, Switzerland and the UK. Belgium, Estonia, Poland and Romania are significantly different in this respect with $20 \%$ or less psychological or social diagnoses for distressed patients. Germany, Spain and Sweden occupy a middle position with $30-40 \%$ psychological and social diagnoses. $(\mathrm{F}=16.37$; $\mathrm{df}$ $=9,946 ; \mathrm{p}<.001$ )

The only patient characteristic increasing the odds of a psychosocial diagnosis is the importance attached by the patient to psychological issues (Table II). On the other hand, patients who are better known to the GP have less chances of being given a psychosocial diagnosis. None of the GP characteristics in the analysis contributed to the odds of a psychosocial diagnosis, although psychosocial task perception had an effect before controlling for "country". Psychosocial diagnoses occur more frequently in consultations with much discussion of psychological topics, in consultations with more eye contact and in longer consultations.

Research question 4: Treatment of distressed patients by GP (Level 3)

An important aspect of treatment for psychological or social problems is informationgiving about the disorder and counselling.

When consultations of all distressed patients are considered, GPs in the Netherlands and Switzerland devote more attention during the consultation to psychosocial topics than GPs in Germany, the UK and the Eastern European countries. $(\mathrm{F}=10.81$; df $=9,946 ; \mathrm{p}<.001)$.
In general, there is slightly more attention for psychosocial topics during the consultation when patients have presented psychosocial symptoms or when the GP has made a psychosocial diagnosis than when all consultations of distressed patients are taken together but such an increase is only visible in some countries: the Netherlands, Poland, Sweden and Switzerland. In other countries, it does not make a difference in time devoted to psychosocial topics, whether psychosocial problems were added to the agenda by patient or GP.

Communication in consultations with psychosocial information goes along with more affective talk (showing empathy), longer consultations and more eye contact.

A final aspect of treatment of patients with psychological problems is the prescription of psychopharmacological medicine. About $10 \%$ of all patients who feel distressed are given a prescription for their psychosocial problem. In the Netherlands and the UK this treatment is significantly more frequently given (in $20 \%$ of the cases) than in the Eastern European countries (less than $5 \%$ of the cases). When patients present symptoms or the GP makes a psychosocial diagnosis, $31 \%$ are treated with pharmaceutical treatment, again most frequently in the Netherlands and the UK.

\section{Discussion and conclusion}

Our analyses reveal that in all countries selective filters are a strong influence on the pathway from demand for help via diagnosis to effective mental health care. The relative differences between countries regarding the prevalence of mental distress (the "point of departure") remain below a factor 2 . When we consider the next coming filters, 
the relative differences between countries, regarding the proportions of those who present symptoms, who are diagnosed or who are treated is a multiple of that factor, rising to $1: 5$ and higher.

It appears that a certain group of patients is diagnosed with a psychological diagnosis without having put forward a psychological symptom or request for help, and in some countries, psychological treatment seems hardly dependent on the presence of symptoms or a diagnosis.

The first filter, help-seeking behaviour, is especially potent in the Eastern European countries from our sample, where 5 percent or less of patients who experience mental distress translate that distress into psychological or social symptoms. The countries where general practice is the natural place for first contact for mental disorder because of the gate-keeping function of general practice, the Netherlands, Spain and the UK, are among the countries with the highest proportion of help-seeking behaviour. But a gate-keeping system does not seem to be a necessary condition, because helpseeking behaviour is frequently seen in Sweden and Switzerland as well.

Regarding the degree to which GPs make psychological or social diagnoses, again, a gate-keeping system seems at least a facilitator. In gate-keeping countries like the UK and the Netherlands, a relatively large proportion of distressed patients get a psychosocial diagnosis; by contrast, in non-gate-keeping countries in Eastern Europe and Belgium the proportion is low. Again, Switzerland is higher than expected, although the remuneration of psychotherapeutic sessions for Swiss GPs might explain their position.

A remarkable finding concerning psychosocial counselling and information giving is the relatively low position of the UK.
Compared with others, British patients are not very reserved in putting forward psychosocial symptoms and British GPs are among the most eager to make psychosocial diagnoses. However, the proportion of distressed patients addressed by the GP in a psychosocial way is low, compared to other countries, such as the Netherlands and Switzerland. Apparently, prescription of psychopharmacological medicine, which we found to be relatively high in the UK and maybe the use of counsellors (no data available) can explain the relatively low position of the UK in this respect.

Psychosocial communication with the patient cannot be considered a gate-keeping issue. In countries without such a system, such as Sweden and Belgium, doctors appear to devote more time to psychosocial information and counselling than doctors in gate-keeping countries like Spain or the UK. In the case of Switzerland, remuneration might be the explanation; in case of Belgium, Switzerland and Sweden, the relatively long consultations (18-20 minutes, average) might be another explanation.

A last feature of treatment is the difference between countries in the pharmaceutical treatment of distressed patients. Medication is given fairly readily in the Netherlands and the UK but hardly at all in Eastern Europe. Doctors in both former countries are among the ones who make a lot of psychosocial diagnoses as well, but that is comparable with Switzerland where the medication rate among patients with a psychosocial diagnosis is low. Maybe remuneration for psychosocial counselling in Switzerland is responsible for a substitution of medication by conversation in that country.

Differences between countries could not be attributed to confounding by patient or GP characteristics. On the other hand, a 
number of patient and GP characteristics appeared to be effective in all countries; one of these is the importance attached to psychological care given by the GP. Distressed patients who have this attitude are more likely to present psychosocial symptoms and consequently to be diagnosed as such. Communication variables like discussing mood and feelings (showing concern and understanding) and eye contact had the expected effect on diagnosis and psychosocial treatment in all countries ${ }^{16}$. Some characteristics, like GP's task perception, lost their significant effect after control for the country level, because task perception has been demonstrated to differ between gatekeeping and non-gate-keeping countries ${ }^{20}$.

Some of the discrepancies between countries reported in this paper may be due to cultural differences regarding the interpretation of questionnaires or observation protocols. Maybe patients in Western Europe are more accustomed to expressing their feelings of distress in a psychosocial wording than Eastern European patients. However, low scores on symptom presentation were found in Belgium and Germany as well.

Some of our indicators are rather general. For "feeling of distress" 1 item from the COOP-WONCA charts was used. However, the response pattern (21\% positive) and the overrepresentation of women and people living alone ${ }^{9,11}$ contribute to its validity.

As far as the problem of untreated mental disorder is concerned, different approaches might be useful in different health care systems or countries. General practitioners in Eastern Europe (and in Belgium and Germany as well) should be aware of the fact that many patients, presenting with somatic symptoms, suffer from feelings of mental distress as well. Public mental health education might be of use in these countries, informing the public that distress can be discussed in primary care. The relatively easy access for the demands of mental help in Switzerland, where extra time devoted to counselling is remunerated, might be inspiring for other countries and health care systems. Lastly, although much distress is not presented, and a lot of signals are not received, in countries like Belgium and Sweden, the large amount of available time provides compensation and results in relatively favourable scores in areas such as psychosocial counselling and education.

\section{References}

1. Murray CJL, Lopez AD. The global burden of disease. Geneva: World Health Organization; 1996.

2. Alonso J, Angermeyer MC, Bernert S, Bruffaerts R, Brugha TS, Bryson $\mathrm{H}$ et al. Prevalence of mental disorders in Europe: results from the European Study of the Epidemiology of Mental Disorders (ESEMeD) project. Acta Psychiatr Scand 2004; 109(s420): 21-27.

3. Goldberg D, Huxley P. Common mental disorders. London: Routledge; 1992.

4. Gater R, De Almeida e Sousa B, Barrientos G, Caraveo J, Chandrashekar CR, Dhadphale $M$ et al. The pathways to psychiatric care: a cross-cultural study. Psychol Med 1991; 21: 761-774.

5. Verhaak PFM, Brink-Muinen A. van den, Bensing JM, Gask L. Demand and supply for psychological help in general practice in different European countries: access to primary mental health care in six European countries. Eur J Public Health 2004; 14(2): 134-140.

6. Brink-Muinen A van den, Verhaak PFM, Bensing JM, Bahrs O, Deveugele M, Gask L, et al. The Eurocommunication Study. An international comparative study in six European countries on doctor-patient communication in general practice. Utrecht: NIVEL; 1999.

7. Weel C van, Konig-Zahn C, Touw-Otten FWMM, Duijn NP van, Meyboom-de Jong B. Measuring functional health status with the COOP/WONCA charts: a manual. WONCA, ERGHO, NCH; 1995. 
8. Boersma JJ, Gebel RS, Lamberts H. International Classification of Primary Care. Utrecht: NHG, 1995.

9. Andrews G, Hall W, Teesson M, Henderson S. The mental health of Australians. Canberra: Mental Health Branch, Commonwealth Department of Health and Aged Care; 1999.

10. Bijl RV, Zessen Gv, Ravelli A. Psychiatrische morbiditeit onder volwassenen in Nederland: het NEMESISonderzoek II: Prevalentie van psychische stoornissen. [Psychiatric morbidity among adults in the Netherlands: the second NEMESIS study: Prevalence of mental disorders] Ned Tijdschr Geneeskd 1997; 141: 2453-2460.

11. Jenkins R, Lewis G, Bebbington P, Brugha T, Farrell M, Gill B et al. The National Psychiatric Morbidity Surveys of Great Britain. Initial findings from the household survey. Psychol Med 1997; 27: 775-789.

12. Kessler RC, McGonagle KA, Zhao S, Nelson CB, Hughes M, Eshleman S et al. Lifetime and 12-month prevalence of DSM-III-R psychiatric disorders in the United States. Arch Gen Psych 1994; 51: 8-19.

13. Toft T, Fink P, Oernboel E, Christensen KS, Frostholm L, Olesen F. Mental disorders in primary care: prevalence and co-morbidity among disorders. Results form the functional illness in primary care (FIP) study. Psychol Med 2005; 35(8): 1175-1184.

14. Verhaak PFM, Schellevis FG, Nuyen J, Volkers AC. Patients with a psychiatric disorder in general practice: determinants of GP's psychological diagnosis. Gen Hosp Psychiatry 2006; 28(2): 125-132.
15. Bensing JM, Kerssens JJ, Pasch M van der. Patientdirected gaze as a tool for discovering and handling psychosocial problems in general practice. Journal of Nonverbal behavior 1995; 19(4): 223-242.

16. Bensing JM, Schreurs K, Rijk A de. The role of physician's affective behaviour in medical encounters. Psychol Health 1996; 11: 825-838

17. Hickie IB, Davenport TA, Scott EM, Hadzi-Pavlovic D, Naismith SL, Koschera A. Unmet need for recognition of common mental disorders in Australian general practice. Med J Aust 2001; 175 Suppl: S18-S24.

18. Marks JN, Goldberg DP, Hillier VF. Determinants of the ability of general practitioners to detect psychiatric illness. Psychol Med 1979; 9: 337-353.

19. Zantinge EM, Verhaak PFM, Kerssens JJ, Bensing JM. The workload of GPs: consultations of patients with psychological and somatic problems compared. Br J Gen Pract 2005; 55(8): 609-614.

20. Boerma, WGW, Verhaak PFM. The general practitioner as the first contacted health professional by patients with psychosocial problems: a European study. Psychol Med 1999; 29: 689-696.

Address for correspondence:

Peter F.M. Verhaak

P.O. box 1568

3500 BN Utrecht

The Netherlands

p.verhaak@nivel.nl

tel.: + 31302729735

fax: + 31302729729 